\title{
NUMERICAL AND EXPERIMNETAL ANALYSIS OF WENNER METHOD IN TWO- HORIZONTAL AND VERTICAL LAYER GROUND \\ Mohamed Nayel
}

Faculty of Engineering, Electrical Engineering Dept., Assiut University, Assiut, Egypt 71518

Received 28January 2014; accepted 31 March 2014

\begin{abstract}
This paper studies the apparent ground resistivity in two-horizontal layer ground and in two-vertical layer ground through the site measurements obtained. Wenner method was used to measure apparent ground resistance in different grounds. A numerical model was proposed to model the four electrode buried in ground. The apparent ground resistivity had been studied for different conditions which are two-horizontal and -vertical layer grounds. Field measurements had been done in various sites close to water channel and also far away from any apparent vertical layer ground. Generally, the calculated results agreed with the measured results. Analytical calculations had been proposed to distinguish between two-horizontal and two-vertical layer ground.
\end{abstract}

Keywords: Four-electrode method, Two layer ground, Vertical layer ground, Horizontal layer ground, Ground resistivity

\section{Introduction}

Ground resistivity measurements have been concerned by many researchers and engineers for a long time. There are many techniques used in measuring ground resistivity. The theoretical basics of obtaining ground resistivity based on injecting a current into a ground through outer electrodes buried into the ground. The resultant potential of inner electrodeswas divided by the injected current and resulted in an apparent ground resistivity. Those methods that incorporate this technique are four electrode method and deep electrode method. These methods relate the measured resistance and physical dimensions of the experiment and ground resistivity. For the four electrode method, the relation between the physical experiment, apparent ground resistivity and measured resistance is as follows [1]:

$\rho_{a}=2 \pi a \frac{V}{I}=2 \pi a R$

where $a=$ the spacing between electrodes $(\mathrm{m}), V=$ the measured voltage between inner pair electrodes $(\mathrm{V}), I=$ the source current between outer pair electrodes (A).

The real ground is not homogenous in vertical and horizontal directions. For more accurate considerations, a two-horizontal layer ground was assumed and the apparent resistivity $\rho_{a}$ formula was as follows $[1,2]$ :

$$
\rho_{a}=\rho_{1}\left(1+4 \sum_{n=1}^{\infty} \frac{k^{n}}{\sqrt{1+\left(\frac{2 n h}{a}\right)^{2}}}-\frac{k^{n}}{\sqrt{4+\left(\frac{2 n h}{a}\right)^{2}}}\right)
$$

Where $h$ : first layer depth, $\rho_{1}$ : first layer resistivity $\Omega . \mathrm{m}, \rho_{2}$ : second layer resistivity $\Omega . \mathrm{m}$, 
$k=\frac{\rho_{2}-\rho_{1}}{\rho_{2}+\rho_{1}}:$ Reflection factor, $\mathrm{n}:$ iterated image number.

Otherwise, numerical methods are used to model the ground as multi-horizontal layer ground to relate between the apparent ground resistivity, ground parameters and physical experiment dimensions [3- 6].

To estimate the ground parameters, different measurements might be done and ground resistivity equations might be solved at these different measurements. By solving these equations, the ground parameters such as ground layers resistivity and depth would be obtained. Different techniques were used to solve these equations. For instance, Newton Raphson method and Genetic algorithm etc. are used [7-12].

As the measurements were done in the field yards and it was a manual practice, someunavoidable errors in measurements which are due to experiment arrangements such as electrode arrangements [13-14] or experiment wires coupling [15-16]. Sometimes the errors were due to the present of external conditions such as the existence of buried metallic structures in ground [17].

The presence of vertical layer ground had been studied before by many researchers [18-22]. The outlook for four electrode method results in vertical layer ground is similar to that of horizontal results.If four electrodes were buried in a two-vertical layer ground, a relation between the experiment physical dimensions, ground parameters and apparent ground resistivity measurements will be as follows [22]:

$$
\begin{aligned}
& \rho_{a}=a \rho_{1}\left(\frac{1}{a}+\frac{k}{\sqrt{4 d^{2}+4 d a \cos \beta+a^{2}}}+\frac{k}{\sqrt{4(d+3 a \cos \beta)(d+2 a \cos \beta)+a^{2}}}\right. \\
& \left.-\frac{k}{\sqrt{4 d^{2}+8 d a \cos \beta+4 a^{2}}}-\frac{k}{\sqrt{4(d+3 a \cos \beta)(d+a \cos \beta)+4 a^{2}}}\right)
\end{aligned}
$$

whered : perpendicular distance between the first electrode and the second layer, $\beta$ : angle between the line where four electrodes lied on with the perpendicular direction to the interface between the two layers.

As the ground may not be homogenous in vertical directions, the assumption of two-horizontal layer ground may not be accurate. The estimated parameters due to this assumption will be inaccurate.. Hereby, this paper studies the characteristics of four-electrode measurements in two-vertical layer ground and two-horizontal layer ground. The comparison between different ground models showed the main differences between these measurements for the engineers to differentiate and decide which model to be utilized. Field measurements had been done to verify the calculated results.

\section{Calculation Model}

\subsection{Case studies}

The ground was modeled as two-horizontal layer ground and two-vertical layer ground, as depicted in Fig. 1. Four electrodes are located at the same line and separated by equal distance " $a$ " from each other. This is illustrated in Figure 1(a).. The top layer ground has resistivity " $\rho_{1}$ " and " $h$ " depth. The bottom layer ground has resistivity " $\rho_{2}$ " and this can be extended to infinity. Figure 1(b) shows four electrodes buried in two vertical layer ground. The four electrodes are located at layer " 1 ". Electrode " 1 " is spaced from the interface surface by distance " $d$ " and the four electrodes are locate at a line and this line made angle " $\beta$ " with perpendicular to the boundary surface. To model the electrodes in different ground, each electrode is divided into " $N$ " balls [23]. To satisfy the boundary between the two layers ground and the air for the vertical and horizontal layer grounds, a successive 
image technique had been assumed as shown in Fig. 2(a) and 2(b). The relationship between the voltage and current can be written as:

$$
\left[\begin{array}{l}
V_{1} \\
. . \\
V_{2} \\
. . \\
V_{3} \\
. . \\
V_{4} \\
. .
\end{array}\right]=\left[\begin{array}{ccccc}
R_{11.11} & R_{11.12} & \ldots & \ldots & R_{11.4 N} \\
\ldots & \ldots & \ldots & \ldots & \ldots \\
\ldots & \ldots & \ldots & R_{o . p} & \ldots \\
\ldots & \ldots & \ldots & \ldots & \ldots \\
R_{4 N .11} & R_{4 N .22} & \ldots & \ldots & R_{4 N .4 N}
\end{array}\right]\left[\begin{array}{l}
I_{11} \\
. \\
0 \\
. \\
0 \\
. \\
I_{41} \\
. .
\end{array}\right]
$$

where $I_{j i}$ is the current of the $i^{\text {th }}$ ball in $j^{\text {th }}$ electrode $(j=1 ; 2 ; 3 ; 4), V_{j}$ is the voltage of the $j^{\text {th }}$ electrode, $R_{o . p}$ is the mutual impedance element, $R_{j n . j n}$ is the self-impedance of the $n^{\text {th }}$ sphere in $j^{\text {th }}$ electrode.

The four electrodes have unknown conducting (equipotential) surfaces $V_{l}, V_{2}, V_{3}$ and $V_{4}$. The summation of currents diffused to the soil from the spheres of outer electrode is equal to other outer electrode with negative value, where the currents of the spheres of two inner electrodes (voltage probes) are equal to 0 . By multiplying the two sides of equation (4) by the inverse of resistance matrix, equation will be as follow:

$$
\left[\begin{array}{l}
I_{11} \\
. . \\
0 \\
. . \\
0 \\
. . \\
I_{41} \\
. .
\end{array}\right]=\left[\begin{array}{ccccc}
G_{11} & G_{12} & \ldots & \ldots & G_{1.4 N} \\
\ldots & \ldots & \ldots & \ldots & \ldots \\
\ldots & \ldots & \ldots & G_{o . p} & \ldots \\
\ldots & \ldots & \ldots & \ldots & \ldots \\
G_{4 N 1} & G_{4 N 2} & \ldots & \ldots & G_{4 N .4 N}
\end{array}\right]\left[\begin{array}{l}
V_{1} \\
. \\
V_{2} \\
. \cdot \\
V_{3} \\
. . \\
V_{4} \\
. .
\end{array}\right]
$$

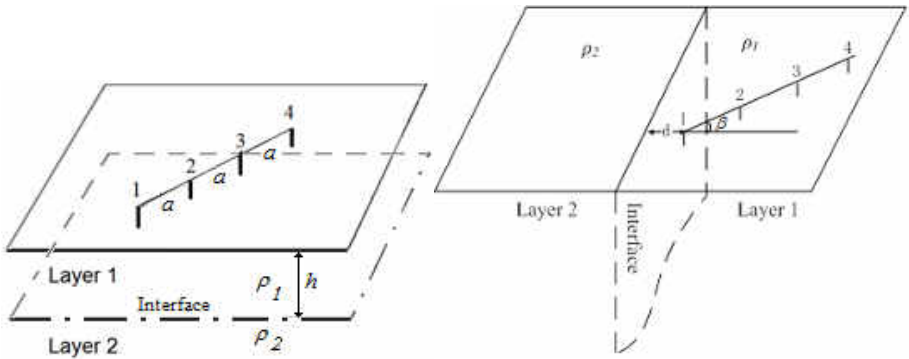

(a) Two-horizontal layer ground model

(b) Two- vertical layer ground model

Fig. 1. Four electrodes arrangement for different ground models

The $G$ matrix in equation (5) are divided into $4 \times 4$ matrixes. The elements of each sub-matrix are summited together. So, equation (5) is minimized to be direct relations between four electrodes voltages and currents as shown in equation (6). 


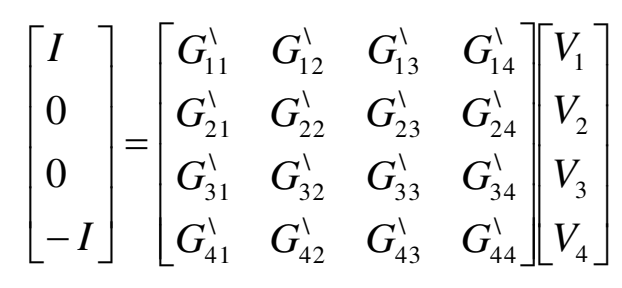

Both sides of equation 6 are multiplied by the inverse of matrix $\mathrm{G}$.

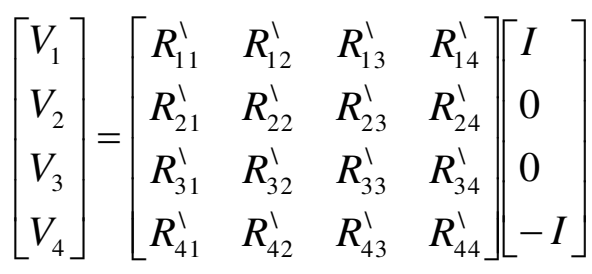

Then, the apparent resistance of the soil is

$$
R_{a}=\frac{V_{2}-V_{3}}{I}
$$

\subsection{Calculated results}

Fig. 3 shows the calculated apparent ground resistivity related to first layer ground for different angle $\beta$, at polar coordination for horizontal and vertical-layer ground. The calculated results are done at reflection factor 0.8182 and -0.8182 . As shown in Fig. 3, the relative apparent ground resistivity at two-horizontal layer ground has no change in the calculated values with respect to the change in angle " $\beta$ " for the similar ground reflection factor 0.8182 and -0.8182 . The relative apparent ground resistivity for vertical two layer ground has a little change when angle $\beta$ near $180^{\circ}$ and $-180^{\circ}$. Otherwise, there is no difference when angle $\beta$ less than $108^{\circ}$ and $-108^{\circ}$.

Fig. 4 shows the calculated relative apparent ground resistivity at two-vertical layer ground with the angle of " $\beta$ " for different distance $a(1 \mathrm{~m}, 5 \mathrm{~m}$ and $10 \mathrm{~m})$ and different reflection factor " $k$ " (0.8182 and -0.8182$)$. For positive reflection factor $(0.8182)$, the relative apparent ground resistivity increases with angle " $\beta$ " as it is close to $90^{\circ}$ and vise verse for negative reflection factor $(-0.8182)$. As the distance " $a$ " increases, the differences in relative apparent ground resistivity also increases.

Fig. 5 shows the calculated relative apparent ground resistivity for two-vertical layer ground with a distance $a$ for different reflection factor (0.8182 and -0.8182) and different distances d $(1 \mathrm{~m}$ and $10 \mathrm{~m})$ when $\beta=90^{\circ}$. As distance " $a$ " increases, the relative apparent ground resistivity increases for positive reflection factor and this resistivity decreases for negative reflection factor. The change in relative apparent ground resistivity increases as distance $d$ decreases. 


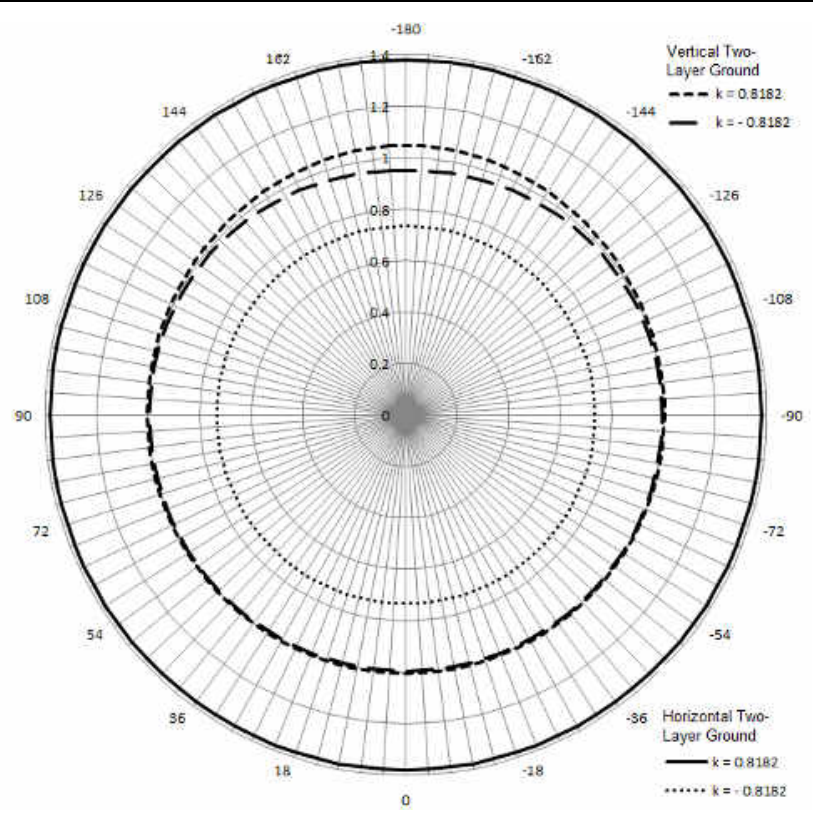

Fig. 3. Relative apparent ground resistivity for different angles $\beta$ at polar coordinates for two- horizontal/vertical layer ground and $k=0.8182$ and -0.8182 .

Fig. 6 shows the calculated relative apparent ground resistivity at two- horizontal layer ground with distance " $a$ " for different reflection factor $k(0.8182$ and -0.8182$)$ and different top layer ground depth $h(1 \mathrm{~m}$, and $10 \mathrm{~m})$. As distance " $a$ " increases as the relative apparent ground resistivity increases for positive reflection factor and vise verse for negative reflection factor. The change in relative apparent ground resistivity increases as top-layer ground depth " $h$ " decreases. The changes in relative apparent ground resistivity with distance " $a$ " in two-horizontal layer ground case, as shown in Fig. 5, is larger than that in two-vertical layer ground case, as shown in Fig. 6.

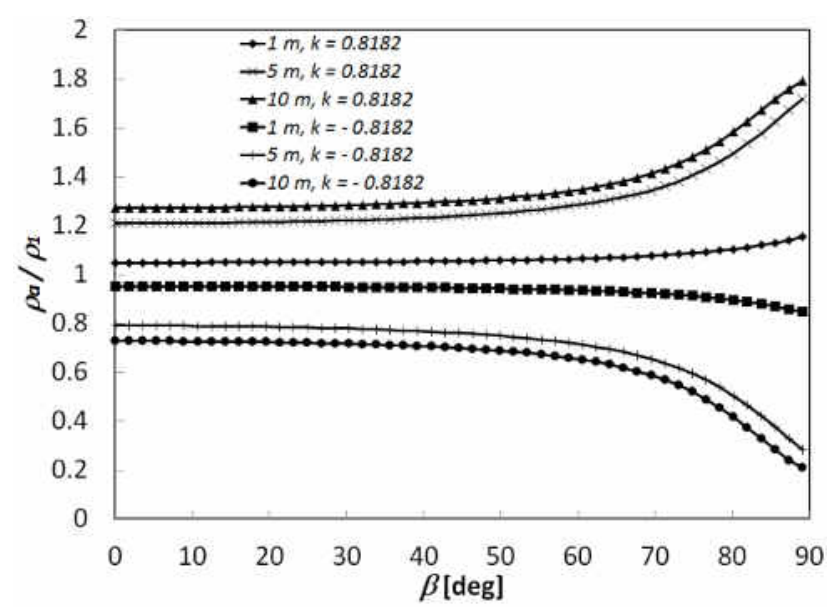

Fig. 4. Relative apparent ground resistivity for different distance $a$ andreflection factor vs. angle $\beta$ for two- vertical layer ground. 


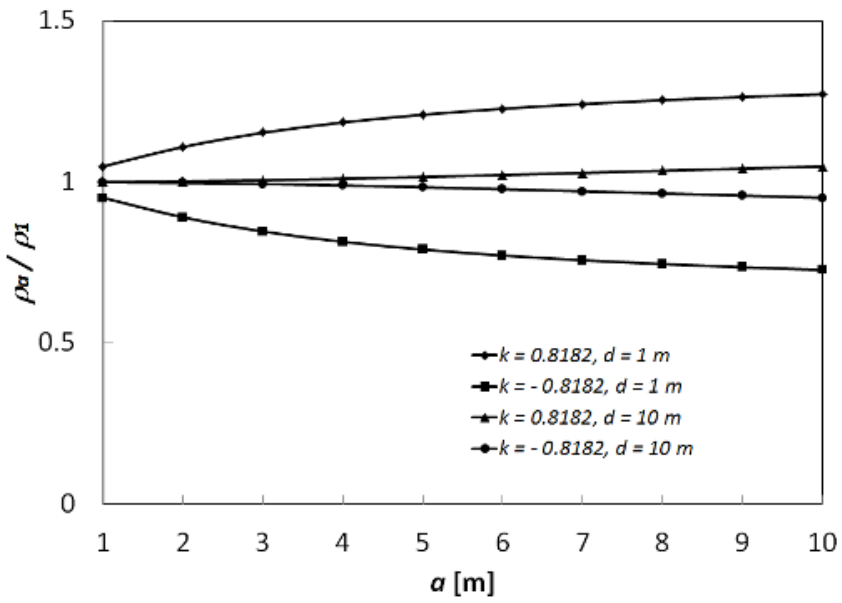

Fig. 5. Relative apparent ground resistivity of different distance $a$ fork $(0.8182$ and $0.8182)$ and $d(1 \mathrm{~m}$ and $10 \mathrm{~m})$ for two- vertical layer ground.

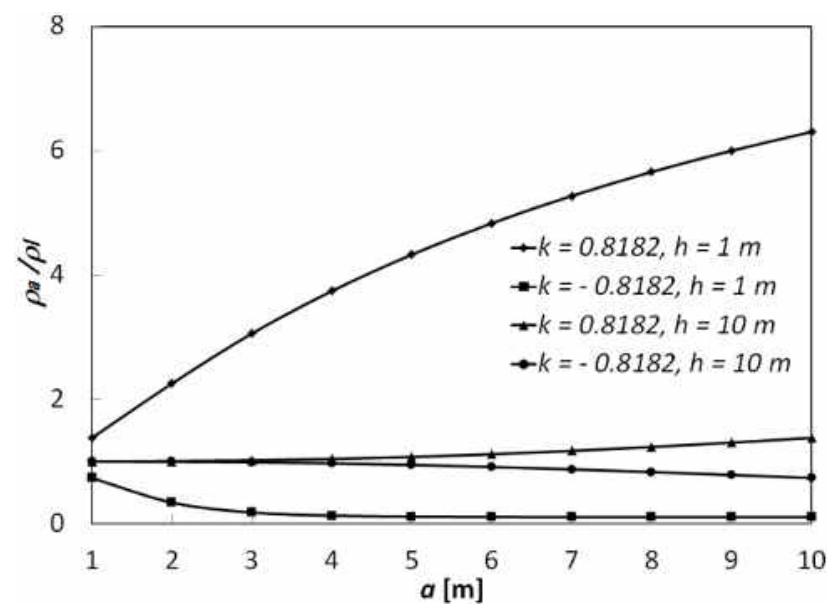

Fig. 6. Relative apparent ground resistivity of different distance $a$ andreflection factor vs. angle $\beta$ for two- horizontal layer ground.

\section{Field measurements}

Many measurements had been carried out to investigate the calculation results. To achieve this goal, six different measurement cases had been done at two different sites. For each case, the measurements were done for different distance " $a$ " (for e.g. 1, 2, 3, 4, 5, 6, 7, $8,9$ and $10 \mathrm{~m})$ as much as possible. These measurements were done twice in two perpendicular directions to test the effect of vertical layer ground on these measurements. The ground tester with Fluke 1623 model was used in these measurements with $\pm 2 \%$ intrinsic error and $\pm 5 \%$ of operating error. 


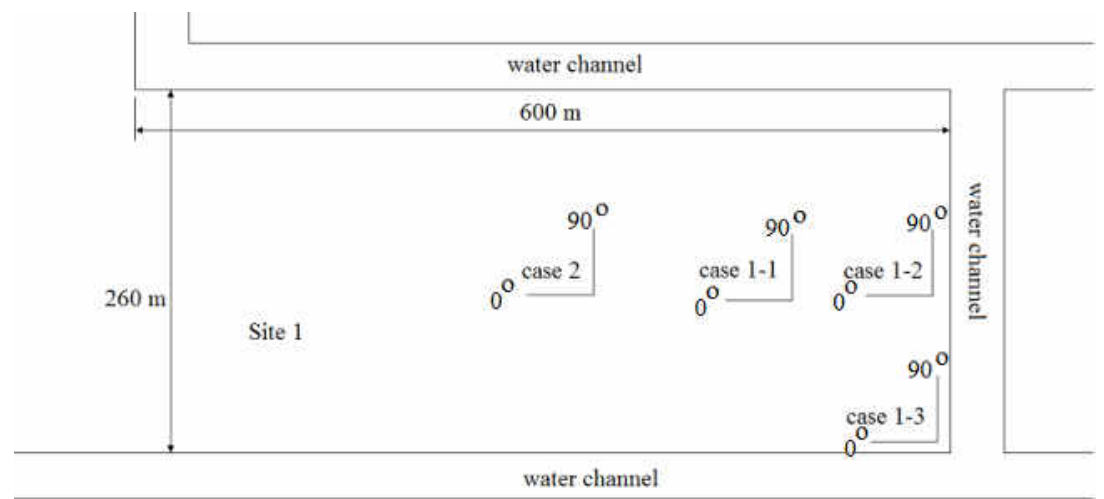

Fig. 7. Sketch for site 1
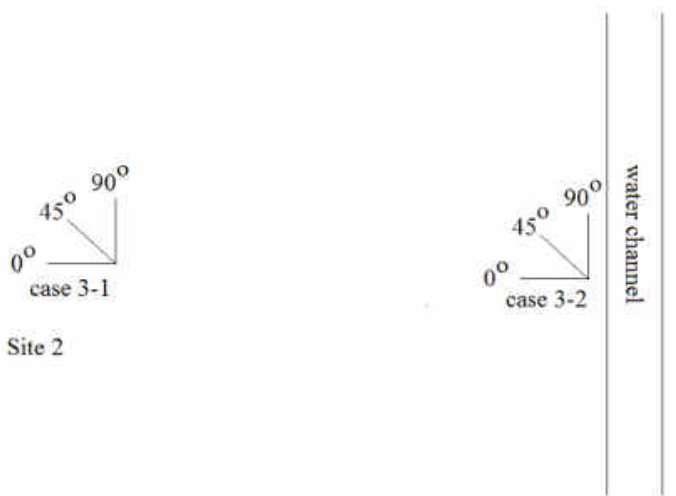

Fig. 8. Sketch for site 2 .

\subsection{Measurement sites}

Site 1 is located at XJTLU university south campus. It is a flat garden of $260 \times 600 \mathrm{~m} 2$ and surrounded by water channels from 3 sides. Fig. 7 shows the locations of studied cases $1-1,1-2,1-3$ and case 2. Site 2 is located at Suzhou Industrial Park (SIP) in the front of the local stadium. It has a huge area and there is a water channel passing through it. Fig. 8 shows the locations of studied cases 3-1 and 3-2. The measurements in site 2 had been made at three directions $0^{\circ}, 45^{\circ}$ and $90^{\circ}$ to ensure that the changes of measured ground resistance are consistent with the change in the angle $\beta$.

\subsection{Measurement results}

Fig. 9 shows the measured ground resistance and obtained apparent ground resistivity at different cases (1-1, 1-2, 1-3, 2, 3-1 and 3-2). The measured ground resistance decreases as distance " $a$ " between electrodes increases. There are no significant differences between the measured ground resistance at $0^{\circ}$ and $90^{\circ}$ directions for the same case. As the measurements are done closer to the water channel (cases 1-1, 1-2, 1-3 and 3-2), the calculated apparent ground resistivities for perpendicular measurements increases. The apparent ground resistivities at far distance from water channels, nearly, they have lower change between the perpendicular directions measurements as in case 2 and case 3-1. Also, these measured results agree consistent with the calculated results in Fig. 3. 


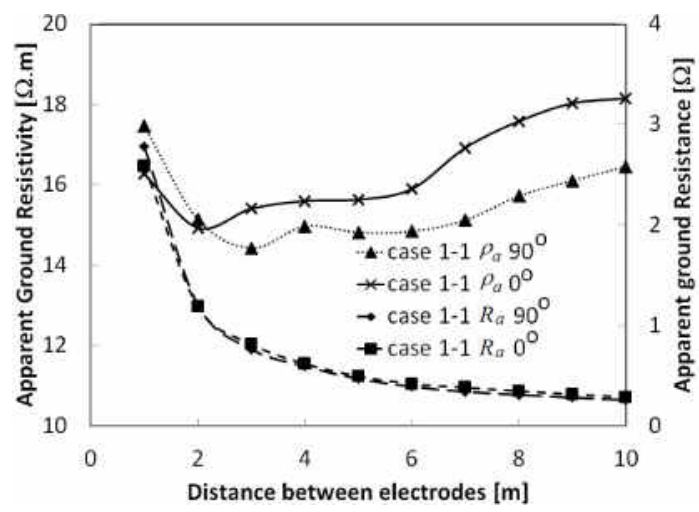

(a) Case 1-1

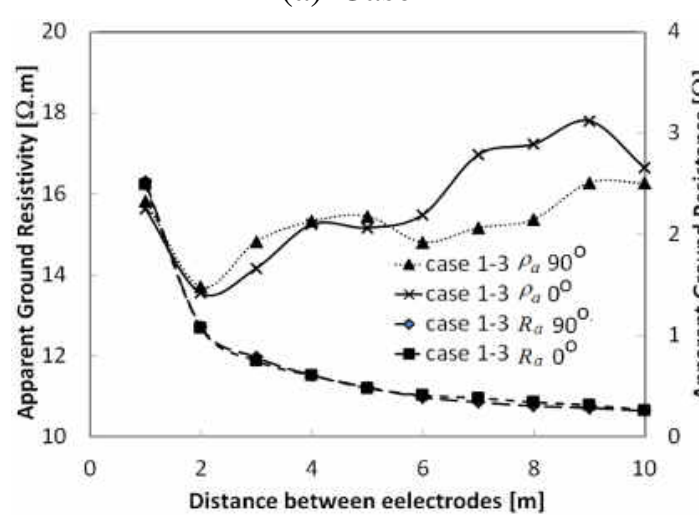

(c) Case 1-3

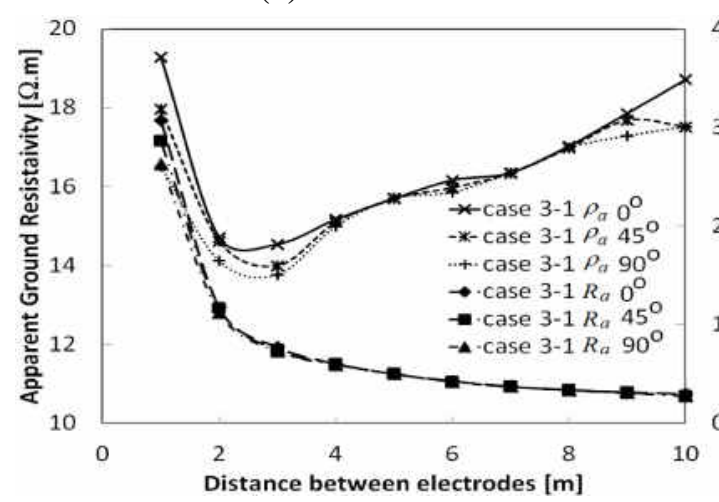

(e) Case 3-1

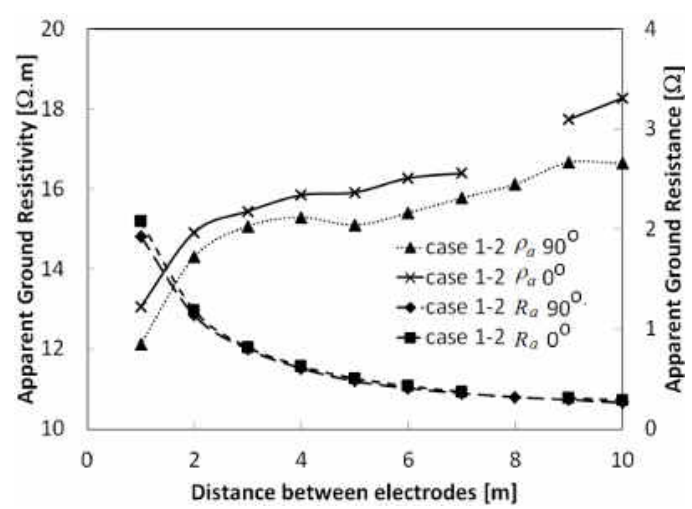

(b) Case 1-2

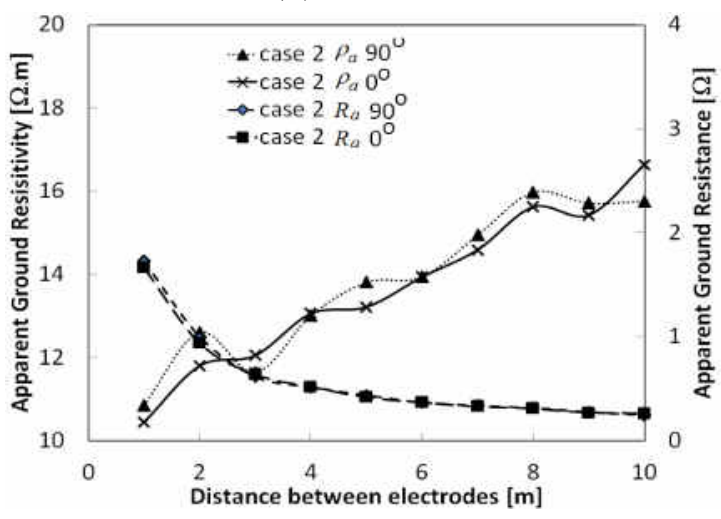

(d) Case 2

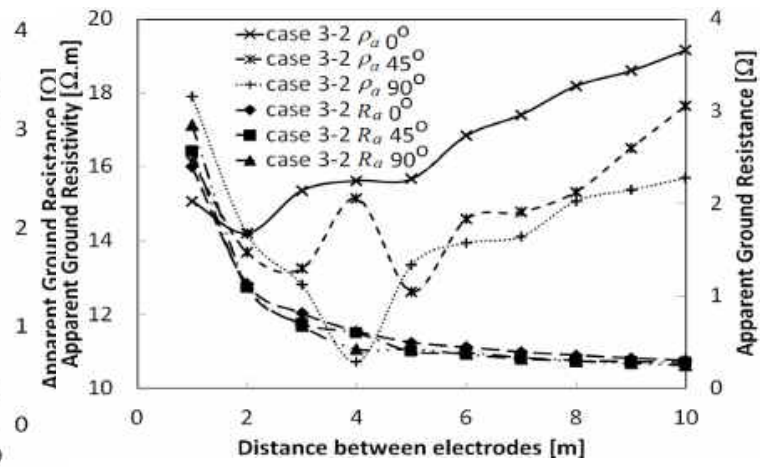

(f) Case 3-2

Fig. 9. Measured apparent ground resistance/resistivity results versus distance $a$ by using four-electrode method.

Table 1 summarizes the average measurements of apparent ground resitivities in two perpendicular directions $\left(\rho_{a 90}{ }^{o}\right.$-avr and $\rho_{a}{ }^{\mathrm{o}}$-avr $)$. The comparison between the measured results 
and the calculated results shows good agreement. The calculated results are calculated for the first layer ground resistivity shown in table 1 at the last column, where the second layer ground resistivity of all cases is equal to zero. The results show that $\rho_{a \text {-avr }}$ is closer to $\rho_{a p \text {-avr }}$ when measurements are far from water channels as the ground is supposed to be horizontal layer ground or uniform ground. On the contrary, the differences tend to be wider for the cases which are closer to the water channels as these are vertical layer ground.

To reduce the random errors, the apparent ground resistivities had been differentiated with distance $a$ and angle $\beta$ as follows:

$$
\delta \rho_{\mathrm{an}}=\operatorname{avr}\left[\left(\rho_{\mathrm{an}-1}-2 \cdot \rho_{\mathrm{an}}+\rho_{\mathrm{an}+1}\right) / 2\right], \quad \delta \rho_{\mathrm{a}-\mathrm{n} \text { ang }}=\operatorname{avr}\left[2\left(\rho_{\mathrm{an} 90^{\circ}}-\rho_{\mathrm{an} 0}{ }^{\mathrm{o}}\right) / \pi\right]
$$

The presence of vertical layer ground $\delta \rho_{a-n}$ ang are much higher than $\delta \rho_{a n}$ as in cases 1-1, 1-2, 1-3 and 3-2 which agrees with calculated results in Figs 3, 4, 5 and 6. The proposed horizontal layer ground $\delta \rho_{d}$ are much higher than $\delta \rho_{a-n \mathrm{ang}}$. These characteristics agree with the characteristics of the differential equations of 1,2 and 3 with distance " $a$ " and angle " $\beta$ ".

Table 1.

Measured/calculated results.

\begin{tabular}{|c|c|c|c|c|c|}
\hline Case & $\rho_{a} 90^{\circ}$-avr & $\rho_{a} 0^{o}$-avr & $\delta \rho_{a \text { ang }}$ & $\delta \rho_{a}$ & $\rho_{1}$ \\
\hline $1-1$ & $15.98 / 15.997$ & $16.44 / 15.998$ & 0.774 & 0.272 & 16.5 \\
\hline $1-2$ & $15.25 / 15.953$ & $14.39 / 15.955$ & 0.530 & 0.233 & 16.5 \\
\hline $1-3$ & 15.30 & 15.79 & 0.484 & 0.441 & - \\
\hline 2 & $13.83 / 13.755$ & $13.68 / 13.755$ & 0.264 & 0.474 & - \\
\hline $3-1$ & $16.55 / 16.498$ & $15.91 / 16.499$ & 0.31 & 0.359 & 16.7 \\
\hline $3-2$ & $16.61 / 16.458$ & $14.32 / 14.221$ & 2.383 & 0.694 & 16.7 \\
\hline
\end{tabular}

\section{Conclusions}

The present of vertical layer ground effects on the four electrode method measurements are investigated in this work. From the results, the measurements at two perpendicular directions can differentiate between vertical and horizontal layer grounds. The change in apparent ground resistivity for two-horizontal layer ground case is much higher than that for two-vertical layer ground case with the increase of the distance between the measurement electrodes. There is no change in measured apparent ground resistivity with the change of measurement directions for two-horizontal layer ground. However, then change is significant in measured apparent ground resistivity with change of measurement directions for two-vertical layer ground. As such, it is recommended to do some structural testing for groundings so as to verify the existence of any vertical or horizontal structure before the installation or design of the grounding system for efficient protection purposes.

\section{References}

[1]E. Sunde, "Earth conduction effects in transmission systems", Dover Publications, Inc. New York, 1968.

[2] T. Takahashi and T. Kawase, "Analysis of apparent resistivity in a multi-layer earth structure", IEEE Transactions on Power Delivery, vol. 5, no. 2, pp. 604-612, April 1990.

[3]B. Thapar, , MT. Bozeman, and V. Gerez, "Equivalent resistivity of non-uniform soil for grounding grid design", IEEE Transactions on Power Delivery, vol. 10 , no. 2, pp. 759 - 767, April 1995.

[4] Y.L. Chow, J.J. Yang and K.D. Srivastava, "Grounding resistance of buried electrodes in multi-layer earth predicted by simple voltage measurements along earth surface - a theoretical discussion", IEEE Transactions on Power Delivery, vol. 10, no. 2, pp. 707-715, April 1995. 
[5]H. Yang, J. Yuan, and W. Zong, "Determination of three-layer earth model from Wenner four-probe test data", IEEE Transactions on Magnetics, vol. 37, no. 5, pp. 3684-3687, September 2001.

[6] T. Taliahashi and T. Kawase, "Calculation of earth resistance for a deep-driven rod in a multi-layer earth structure”, IEEE transactions on power delivery vol. 6, no 2, pp. 608-614, April 1991.

[7]Fani E. Asimakopouloua, George J. Tsekourasb, Ioannis F. Gonosa and Ioannis A. Stathopulosa, "Estimation of seasonal variation of ground resistance using Artificial Neural Networks", Electric Power Systems Research, vol. 94, pp. 113-121, 2013.

[8]J. L. del Alamo, "A second order technique for an improved estimation of soil parameters in a two-layer earth", IEEE Transaction on Power Delivery, vol. 6, no. 3, pp. 1166-1170, July 1991.

[9] Hans R. Seedher, J. K. Arora and Chandigarh, “Estimation of two layer soil parameters using finite Wenner Resistivity expressions", IEEE Transactions on Power Delivery, vol. 7, no. 3, pp. 1213-1217, July 1992.

[10]B. Zhang, X. Cui, L. Li and J. He," Parameter estimation of horizontal multilayer earth by complex image method", IEEE Transactions on Power Delivery, vol. 20, no. 2, pp. 1394-1401, April 2005.

[11]Ioannis F. Gonos, Vassiliki T. Kontargyri and Ioannis A. Stathopulos," XVII International Conference on Electromagnetic Disturbances EMD’2007, Bialystok, Poland, pp. 10.1, Sept. 19-21, 2007.

[12]Ioannis F. Gonos and Ioannis A. Stathopulos, "Estimation of multilayer soil parameters using genetic algorithms", IEEE Transactions on Power Delivery, vol. 20, no. 1, pp. 100-106, January 2005.

[13]C. Wang, T. Takasima, T. Sakuta and Y. Tsubota, "Grounding resistance measurement using fall-of potential method with potential probe located in opposite direction to the current probe", IEEE Transactions on Power Delivery, vol. 13, no. 4, pp. 1128-, October 1998.

[14]J. Ma, F. P. Dawalibi," Extended analysis of ground impedance measurement using the fall-of-potential method", IEEE Transactions on Power Delivery, vol. 17, no. 4, pp. 881-885, October 2002.

[15]J. Ma, F. P. Dawalibi," Influence of inductive coupling between leads on resistivity measurements in multilayer soils", IEEE Transactions on Power Delivery, vol. 13, no. 4, pp. 999-1004, October 1998.

[16]Jinxi Ma and Farid P. Dawalibi, "Influence of Inductive Coupling Between Leads on Ground Impedance Measurements Using the Fall-of-Potential Method”, IEEE Transactions on Power Delivery, vol. 16, no. 4, pp. 739-743, October 2001.

[17]J. Ma, F. B. Dawalibi, "Study of influence of buried metallic structures on soil resistsivity measurements", IEEE Transactions on Power Delivery, vol. 13, no. 2, pp. 356-365, April 1998.

[18]P. D. Rancid, Z. P. Stajic', B. S. Tosic and Djordje R. Djordjevic, "Analysis of linear ground electrodes placed in vertical three-layer earth", IEEE Transactions on Magnetics vol. 12, no. 3, pp. 1505-1508, May 1996.

[19]R. Zeng, J. He, Y. Gao, J. Zou and Z. Guan, "Grounding resistance measurement analysis of grounding system in vertical-layered soil” IEEE Transactions on Power Delivery, vol. 19, no. 4, pp. 1553- 1559, October 2004.

[20]X. Cao, G. Wu, S. Li, W. Zhou and R. Li, “A Simple formula of grounding grid resistance in vertical two-layer soil", Transmission and Distribution Conference and Exposition, 2008. T\&D. IEEE/PES, Chicago, IL USA, pp. 1-5, 21-24,April 2008

[21]F. H. Slaoui, S. Georges, F. Erchiqui," Interpretation of resistivity sounding data for multi-layer vertical earth model", 201121 st International Conference on Systems Engineering, pp. 77 - 81, Las Vegas, NV USA, pp. 77-81, 16-18, August. 2011.

[22]M. Nayel, Boyang Lu and Yu Tian," Study of Soil Resistivity Measurements in Vertical Two-Layer Soil Model” APEEC2012, 2012 Asia-Pacific Power and Energy Engineering Conference, Shanghai, China, March 27-29, 2012).

[23]M. Abdel-Salam, . Ahmed, M. Nayel and AboelsoodZidan," Surface Potential and Resistance of Grounding Grid Systems in Homogeneous Soil” Electric Power Components and Systems, vol. 35, no. 10, pp. 1093-1109, October 2007. 
تحليل طريقة وينر باستخدام طريقة عددية و عملية فيارض ذات طبقتين أفقيتين و رأسيتين

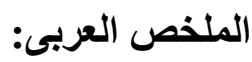

تدرس هذه الورقة مقاومة الأرض النو عية الظاهرية في ارض ذات طبقتين أفقيتين و رأسيتين منخلال قياسات تم الحصول عليها من مو اقع مختلفة. وذللك باستخدام أسلوب وينر لقياس المقاومة النوعية الظاهرية للأرض في ظروف مختلفة. واقترح نموذج عددي لتمثيل الاقطاب الأربعة المدفونة في الأرض. ولقد درست مقاومة الأرض الظاهرية لظروف مختلفة على أساس طبقتين أفقيتين و رأسيتين .أنجزت القياسات الميدانية في مو اقع مختلفة بالقرب من قناة للمياه و أيضا بعيدا فى أرض بلا طبقات رأسية ظاهرية واضحة. و بوجه عام لقد اتفقت النتائج المقاسة مع النتائج الحسابية. و لقد تم افتر اض طريقة عددية تحليلية للتمييزبين ارض ذات طبقتين أفقيتين و رأسيتين . 